\title{
COMMENTARY
}

\section{Expect the unexpected: clinical trials are key to understanding post-intensive care syndrome}

\author{
Michael F O'Connor* and Mark E Nunnally \\ See related research by Wittbrodt et al., http://ccforum.com/content/17/2/R58
}

\begin{abstract}
Long-term follow-up of randomized prospective trials of treatments in the intensive care unit may allow us to attain some understanding of the causes of postintensive care syndrome. This in turn may allow us to produce better long-term outcomes among survivors of critical illness.
\end{abstract}

In the previous issue of Critical Care, Wittbrodt and colleagues [1] report the results of their long-term follow-up of human subjects from a randomized trial comparing hydroxyethyl starch and Ringer's acetate solution. At first glance, the authors' observations appear to be pedestrian and could be misperceived as a trivial addition to the literature. In truth, this study could represent one of the most important contributions in critical care medicine in the past decade.

In the past decade, focus has shifted beyond the outcomes of 28-day and in-hospital mortality [2]. Critical care practitioners understand that patients and their families seek more than mere survival; they seek the highest quality of life possible [2]. A new syndrome, postintensive care syndrome (PICS), has been defined, and there are calls to investigate the basic science mechanisms underlying the myriad problems afflicting critical illness survivors and strategies to avoid or mitigate them [2]. PICS is obviously not a single entity; it has multiple causes and protean manifestations. In survivors, some of their medical problems are almost certainly a consequence of their critical illness (for example, sepsis), whereas others are almost certainly a consequence of underlying disease progression. The only thing we know for certain is that almost every organ system is affected.

*Correspondence: moc5@dacc.uchicago.edu

Section of Critical Care Medicine, Department of Anesthesia \& Critical Care, The University of Chicago, 5841 S. Maryland MC-4028, Chicago, IL 60637, USA
Although the need for systematic bench and clinical investigation of PICS is apparent, there are no obvious resources to make progress across the research agenda [3]. Clinical follow-up will be of great benefit to patients and their families but will be less useful in generating the kind of data that will allow us to better understand the complex pathophysiology in this diverse group of patients [4]. Although massive databases are attractive, data mining from them has not fulfilled the promise that many sought 10 or 20 years ago. What is needed instead is a careful evaluation for the role that every therapy might play in producing or mitigating PICS.

The study by Wittbrodt and colleagues documents a strong association between resuscitation with hydroxyethyl starch and both increased bodily pain and decreased mental health quality of life 14 months after the index intensive care unit (ICU) admission. The authors are unclear about whether the moderate differences in these outcomes are meaningful to patients, but the outcomes are nonetheless real. The authors did not demonstrate a difference in the incidence of pruritis, which appears to be the outcome difference they anticipated in their survey of their survivors. The authors are to be commended on their long-term follow-up and for gathering and analyzing the data for publication in the literature.

If their data have a weakness, it is that their preconceived ideas shaped the data they collected. The history of medicine teaches us that our understanding is much more shallow than generally appreciated and that, if we asked the right questions or gathered the right data, we would learn more. By what mechanism did hydroxyethyl starch cause this long-term difference in bodily pain and mental quality of life? We have no idea. Neither has been previously described as a complication of resuscitation with hydroxyethyl starch, but now they should be. What else of importance might the authors have learned if they had had a broader vision and a more detailed follow-up of their survivors? No one knows. Regardless, Wittbrodt and colleagues have established an important precedent: whenever possible, clinical trials of ICU patients should incorporate long-term follow-up in 
survivors to assess the role that the treatment in the trial might have played in causing or mitigating the aftermath of critical illness. Most such studies will likely make minor contributions to our understanding, but others may document pivotal findings. Given the choice, our patients and their families would prefer that we choose treatments that produce a better quality of life in survivors.

\section{Abbreviations}

ICU, intensive care unit; PICS, post-intensive care syndrome.

\section{Competing interests}

The authors declare that they have no competing interests.

Published: 12 June 2013

\section{References}

1. Wittbrodt P, Haase N, Butowska D, Winding R, Poulsen JB, Perner A; the 6 S trial group and the Scandinavian Critical Care Trials Group: Quality of life and pruritus in patients with severe sepsis resuscitated with hydroxyethyl starch. Long-term follow-up of a randomised trial. Crit Care 2013, 17:R58.

2. Needham DM, Davidson J, Cohen H, Hopkins RO, Weinert C, Wunsch H, Zawistowski C, Bemis-Dougherty A, Berney SC, Bienvenu OJ, Brady SL, Brodsky MB, Denehy L, Elliott D, Flatley C, Harabin AL, Jones C, Louis D, Meltzer W, Muldoon SR, Palmer JB, Perme C, Robinson M, Schmidt DM, Scruth E, Spill GR, Storey CP, Render M, Votto J, Harvey MA: Improving long-term outcomes after discharge from intensive care unit: report from a stakeholders' conference. Crit Care Med 2012, 40:502-509.

3. Coopersmith CM, Wunsch H, Fink MP, Linde-Zwirble WT, Olsen KM, Sommers MS, Anand KJ, Tchorz KM, Angus DC, Deutschman CS: A comparison of critical care research funding and the financial burden of critical illness in the United States. Crit Care Med 2012, 40:1072-1079.

4. Davidson JE, Jones C, Bienvenu OJ: Family response to critical illness: postintensive care syndrome-family. Crit Care Med 2012, 40:618-624.

\section{doi:10.1186/cc12725}

Cite this article as: O'Connor MF, Nunnally M: Expect the unexpected: clinical trials are key to understanding post-intensive care syndrome. Critical Care 2013, 17:149. 